\title{
The Evolutionary Characteristics of Reservoir Microstructure under Long-Term Waterflooding Development and Its Fractal Description
}

\author{
Fengjiao Wang, ${ }^{1,2}$ Xu Wang, ${ }^{1}$ Yikun Liu $\left(D,{ }^{1}\right.$ Qingjun Deng, ${ }^{3}$ Jianjun $X{ }^{4},{ }^{4}$ Yong Zhang, ${ }^{5}$ \\ and Huaiyuan $\mathrm{Li}^{6}$ \\ ${ }^{1}$ Laboratory of Enhanced Oil Recovery of Education Ministry, Northeast Petroleum University, Daqing, 163318 Heilongjiang, China \\ ${ }^{2}$ Daqing Oilfield Co. Ltd., Postdoctoral Res Ctr, Daqing, Heilongjiang 163453, China \\ ${ }^{3}$ No. 1 Oil Production Plant CNPC (China), Daqing, Heilongjiang 163318, China \\ ${ }^{4}$ Chongqing Branch of Daqing Oilfield Co. Ltd., Daqing 163001, China \\ ${ }^{5}$ Yingtai Oil Production Plant of Jilin Oilfield, Songyuan, Jilin 138000, China \\ ${ }^{6}$ Oil \& Gas Engineering Institute of Jilin Oilfield Company, Jilin 138000, China
}

Correspondence should be addressed to Yikun Liu; shenliujili@163.com

Received 26 February 2021; Revised 30 April 2021; Accepted 22 May 2021; Published 9 June 2021

Academic Editor: Guanglei Zhang

Copyright ( $\odot 2021$ Fengjiao Wang et al. This is an open access article distributed under the Creative Commons Attribution License, which permits unrestricted use, distribution, and reproduction in any medium, provided the original work is properly cited.

\begin{abstract}
Generally, long-term waterflooding development often leads to the change of reservoir pore and clay mineral composition, which results in the change of permeability and wettability. In order to explore the relationship between core micropore structure and water cut, based on physical simulation experiments and fractal theory, we proposed a fractal evolutionary model to describe the evolution characteristics of microstructure of long-term water driving reservoirs. In this paper, core pore structure by SEM was first conducted to analyze the change of core pore structure before and after waterflooding under the conditions of magnification of 200 times, 800 times, and 2000 times, respectively. Then, conventional and constant rate mercury injection tests were combined to perform the comparative analysis of core structural parameters before and after waterflooding. Finally, a micropore-throat structure evolution model of core was established. Research shows that the connectivity of larger pores becomes better after long-term water driving, the degree of heterogeneity weakens, and the micro heterogeneity of small pores becomes stronger and stronger. The throat characteristics change in a complex manner, the radius tends to increase, and the sorting becomes better, while the connectivity of small throat changes complex. In general, the heterogeneity of throat increases with the time of water injection in reservoirs with low porosity and permeability. On the basis of fractal theory and variation characteristics of rock pore structure in water driving reservoirs, we have established a micropore-throat structure evolution model of core pore-throat characteristics. This fractal evolution model quantitatively characterized the complexity and evolution law of pore structure and clarified the relationship between fractal dimension of core pore structure and water cut under different stages of water driving.
\end{abstract}

\section{Introduction}

Daqing Oilfield is the largest continental multilayer sandstone reservoir in China. After more than 60 years of longterm water injection development, the comprehensive water cut is over $95 \%$, and it has been fully entered and is a typical representative of ultrahigh water cut oilfield [1-3]. The longterm waterflooding development results in the change of res- ervoir pore and clay mineral composition, which leads to the change of permeability and wettability. The permeability of reservoirs with high permeability greater than $1300 \times 10^{-3}$ $\mu \mathrm{m}^{2}$ increases, while that of reservoirs with permeability lower than $300 \times 10^{-3} \mu \mathrm{m}^{2}$ decreases, and the static heterogeneity of reservoirs intensifies [4]. With the further increase of water cut, especially in the extra high water cut period, the oil and water two-phase seepage capacity are increasing, and the 
water phase permeability is rising sharply, resulting in serious low efficiency and invalid circulation, greatly reducing the development efficiency, and causing great economic losses. In particular, long-term waterflooding leads to low resistance seepage channel at the bottom of highpermeability layer, which is usually called "dominant seepage channel" or "large channel." It makes the injected fluid channeling and greatly reduces the utilization rate of injected fluid, which is very unfavorable for reservoir development.

In Sazhong study area of Daqing Oilfield, there are fluvial-delta facies deposits under the condition of large shallow lake basin. There are 11 types of sand bodies, including flood plain facies, distributary plain facies, delta inner front facies, and delta outer front facies. The total thickness of the strata is about $500 \mathrm{~m}$, and it is composed of 10 oil layer groups, 43 sandstone groups, 144 small layers, 158 subdivided sedimentary units, and hundreds of small sand beds and argillaceous rocks. The permeability difference of the single layer is as high as dozens to more than one hundred times, and the thickness of the single layer is from $0.2 \mathrm{~m}$ to $20 \mathrm{~m}$, which superimposed each other vertically and distributed staggered on the horizontal surface. The sedimentary microfacies developed and formed a very complex reservoir system. The average viscosity of crude oil is $9.2 \mathrm{mPa}$. $\mathrm{s}$. The permeability is in the range of $100 \times 10^{-3} \mu \mathrm{m}^{2}$ to $2000 \times$ $10^{-3} \mu \mathrm{m}^{2}$, and most of them are in the range of $500 \times 10^{-3}$ $\mu \mathrm{m}^{2}$ to $1500 \times 10^{-3} \mu \mathrm{m}^{2}$. The development of oilfield in Sazhong study area was a gradual process. During the 60 years of development, the exploit objects changed from thick layers to thin layers, the strata combination gradually refined division, the injection-production well spacing changed from large to small, and the reserve utilization changed from good to bad. From the perspective of the whole Daqing Oilfield, the reservoir physical properties of Sazhong study area are very well, and the long-term injection fluid development leads to the development of dominant seepage channels. Therefore, in the ultrahigh water cut stage, the phenomenon of inefficient and ineffective circulation is extremely serious. In the final analysis, it is the change of microscopic pore-throat structure caused by long-term injection fluid erosion in these formations, which leads to the change of seepage law.

Reservoir pore structure heterogeneity is one of the key factors of oil remaining distribution and EOR (enhanced oil recovery), especially in the long-term waterflooding reservoir. The long-term waterflooding will lead to the change of reservoir microscopic pore structure. In this case, the quantitative study of the changing law of the reservoir microscopic heterogeneity is the most important to guide the adjustment of oilfield scheme, quantitative description of remaining oil, tertiary oil recovery, and EOR. A large number of scholars domestic and overseas have done a lot of related research on this issue and have obtained rich research results. The research methods mainly include the following: well logging data evaluation method [5], laboratory rock casting thin section [6], scanning electron microscope (SEM) [7], nuclear magnetic resonance (NMR) [8], and conventional highpressure mercury injection [9], as well as two emerging technologies, namely, fractal theory and CT scanning method to construct network model, for qualitative, semiquantitative, and quantitative description of reservoir pore structure [10, 11]. Golsanami et al. [12] divided the target area under the T2 curve by NMR into eight porosity bins and estimated each bin's value from the seismic attributes using neural networks (NN). Their research work showed that by using the incremental porosity under the T2 curve, this curve could be synthesized using the seismic attributes. Thomeer and Libny et al. applied the conventional mercury injection experiment method to test capillary pressure curve, and they had obtained the pore-throat size, connectivity, and the parameters of the seepage ability $[13,14]$. The constant speed mercury injection experiment method had been more and more applied to the study of pore structure, as it could overcome the disadvantages of conventional high-pressure mercury intrusion method with better quantitative characterization of reservoir microscopic pore structure [15]. Meanwhile, the geomechanical properties of the reservoir could not be neglected while studying the porosity-permeability changes. Golsanami et al. introduced a novel approach to obtain geomechanical parameters through investigating the relationship between geomechanical parameters and Archie's coefficients. The obtained results of this study provided new insights into the simultaneous evolution of the reservoir's mechanical and petrophysical characteristic [16]. Many domestic scholars have studied the variation law of reservoir physical property parameters after long-term waterflooding development, mainly through laboratory waterflooding experiments and coring tests. Guan et al. [17] applied laboratory experimental data such as oil well sealed coring and long core waterflooding experiment in the ultrahigh water cut period to study the variation law of physical property parameters and pore structure parameters. The study concluded that with the intensities of reservoir waterflooding, reservoir physical property parameters, pore structure parameters, and seepage characteristics all changed fundamentally. $\mathrm{Wu}$ et al. [18] study the sandstone reservoir physical characteristics and the changing law of the reservoir parameters, and research showed that due to long-term waterflooding, the permeability of sandstone reservoir and moisture content increased, the stratigraphic particles were rushed out, and clay mineral containing basin reduces clever grain of support way and the pore network connectivity, higher permeability, and reservoir wettability by oil into strong hydrophilic. Yin [19] studied through many years the testing data of inspection wells and laboratory core waterflooding experiment of distributary channel sand body of Daqing Oilfield waterflooding process reservoir parameter variation characteristics, and it showed that after long-term water erosion, sample average pore-throat radius and median pore-throat radius, pore throat in reservoir large number, and the permeability contribution rate increase. Li [20] believed that the dynamic geological process of reservoir development fluid was the main reason for the change of reservoir macro parameters. The connectivity of pore throat was improved, the separation of throat was better, the clay minerals were reduced, and the wettability of rock particles was transformed to hydrophilic.

Currently, the fractal geometry, which is an effective tool to characterize the pore structure of reservoirs [21-23], is 
widely utilized when conducting the research on pore and throat analysis. Katz and Thompson [24] first used fractal geometry theory to analyze pore structure in porous media and pointed out that both pore space and pore interface of porous media have fractal structure. It is demonstrated that the multiscale and statistically self-similar fractal behavior is always observed for the pore structure of porous media $[25,26]$. Angulo et al., Perez and Chopra, Shen et al., Li, Li and Horne [27-31], and many other scholars domestic and overseas had put forward different mathematical models to calculate the fractal dimension of pore structure using mercury intrusion data combined with fractal theory and achieved many remarkable results. Li and Zhao [32] derived a mathematical model for determining oil production of spontaneous imbibition by the fractal theory for tight oil reservoir. And the fractal production mode showed a power law relationship between the oil production rate of spontaneous imbibition and time. Chen et al. [33] developed a theoretical model of liquid flow through porous media and numerically analyzed to investigate the role of pore structure on liquid flow behaviors in porous media. In the model, the Sierpinski fractal was utilized to construct the geometry structure of porous media. In the study of Chen et al. [34], they demonstrated that one special bridge function, which was a function of the apparent length and tortuosity fractal dimension, could characterize the relationship of pore structures between two dimensions (2-D) and three dimensions (3-D), and it could serve as a conversion bridge of the radius to determine the capillary pressure curve. In view of the evolution characteristics of micropore-throat structure of longterm waterflood reservoir, most scholars described it through laboratory experiments and field coring data, but few scholars proposed to apply fractal theory to it to realize the quantitative characteristics of its change law in theory.

In this paper, we studied and analyzed the influence and evolution mechanism of long-term waterflooding development on the microscopic pore structure of rocks. Firstly, the structural characteristics of cores before and after longterm waterflooding development were compared by scanning electron microscopy (SEM) under the conditions of magnification of 200 times, 800 times, and 2000 times, respectively. Then, combined with conventional and constant rate mercury injection tests, the effects of long-term water injection before and after on core pore radius distribution, throat radius distribution, permeability contribution rate, and other parameters were studied. And on that basis, based on the fractal theory and the evolution model of pore structure in different water cut stages during long-term water injection, a micropore-throat structure evolution model of core was established, and the mathematical relationship between water cut and fractal dimension of pore structure of core was obtained, which quantitatively characterized the complexity and evolution law of pore structure.

\section{Materials and Methods}

2.1. Experimental Materials. The experimental oil was simulated oil, which was a mixture of degassed and dehydrated crude oil and light hydrocarbon oil in Daqing Oilfield. The viscosity of the simulated oil was $8.86 \mathrm{mPa} \cdot \mathrm{s}$ at $45^{\circ} \mathrm{C}$. The experimental water was prepared from No. 1 oil production plant of Daqing Oilfield. The experimental cores were natural cores, which were taken from the type-I formation of No. 1 oil production plant in Daqing Oilfield. The diameter of natural core was $2.5 \mathrm{~cm}$, and the permeability was in the range of $100 \times 10^{-3} \mu \mathrm{m}^{2}$ to $2000 \times 10^{-3} \mu \mathrm{m}^{2}$.

2.2. Instrument and Facilities. The main instrument used in the experiment include conventional mercury injection meter, conventional mercury injection meter, and constant speed mercury meter. The microscopic pore structure parameters of the core were measured by conventional mercury injection apparatus and constant speed mercury meter. Fei Tecnai G2 F20 scanning electron microscope (SEM) from Gatan Company, USA, was used to test the micromorphology of natural core before and after long-term water driving.

2.3. Experimental Methods. In this paper, we mainly did three aspects of the research work. Firstly, the core profiles before and after long-term waterflooding development were observed by SEM, and the changes of microscopic pores and throat characteristics were compared. Moreover, the evolution characteristics of core pore radius, throat radius, permeability contribution rate, and other parameters before and after long-term waterflooding development were compared and analyzed by conventional mercury injection test and constant rate mercury injection experiment. Finally, the fractal model of long-term water driving core under different water cut conditions was established based on fractal theory. The specific research methods are as follows.

2.3.1. Scanning Electron Microscopy Methods of Natural Cores. (1) Sample preparation: use a burette to absorb a small amount of core debris, evenly spread it in a clean and fixed sample box, and number it for standby; (2) freezing and drying the samples: transferring the prepared samples to E7400 cryotrans to freeze the table quickly, pouring liquid nitrogen for freezing and vacuumizing slowly, then raising the temperature quickly, and sublimating the water in the samples after freezing to obtain dry samples; (3) gold spraying: the sample was placed in a high-voltage electric field with a certain degree of vacuum, the high-voltage electric field ionized the air, and then, a conductive metal film was plated on the surface of the sample; (4) scanning electron microscope: the samples were placed under the scanning electron microscope and observed in the sample room. The pictures were selected to observe the micromorphology of each sample, and the changes of core microstructure before and after waterflooding were compared and analyzed

2.3.2. Method of Mercury Intrusion Test. (1) The natural cores with a diameter of about $2.5 \mathrm{~cm}$ were selected, and the natural cores must be dried after washing with toluene oil. (2) Determine the physical properties of the target cores, including gas permeability, volume, mass, and density. For the conventional mercury injection test: (3) put the target cores into the core chamber of mercury injection instrument, injected mercury under the set pressure, recorded the pressure value and mercury volume after the pressure was stable, 
increased the injection pressure, and repeated the record of the above experimental data. For the constant speed mercury injection test: (4) the target core was put into the core chamber of mercury instrument, and mercury was injected into the throat and pore of rock sample at a very low constant speed $(0.00005 \mathrm{ml} / \mathrm{min})$, so as to ensure that the mercury injection process was carried out under quasi-static state. It was assumed that the interfacial tension and contact angle remain unchanged during the mercury injection process, and the capillary system pressure increases gradually as mercury entered the throat. At the moment when mercury broke through the throat limit and enters the pore, the mercury pressure was released and the whole system pressure fell back. (5) It was considered that the injection pressure was equivalent to the capillary pressure corresponding to the pore space of mercury, and the capillary radius corresponding to the capillary pressure was equivalent to the pore-throat radius of the core. The capillary pressure curve could be obtained by continuously increasing the injection pressure. Combined with the volume of mercury, the distribution probability corresponding to different pore radius ranges could be calculated.

\subsubsection{Fractal Evolution Model Establishment of Microscopic} Pore-Throat Structure after Long-Term Waterflooding. The spatial distribution of pore and throat in porous media has statistical self-similarity [35-37]. The characteristic parameters of pore structure obtained by SEM test and mercury injection method cannot reflect the general law of pore spatial distribution and quantitatively characterize the selfsimilarity of pore structure. Based on mercury injection test data and fractal geometry theory, the theoretical model of evolution characteristics of microscopic pore throat in longterm water-driven cores was established, which was of significance for analyzing the change of core structure parameters under the action of water injection scour.

According to the fractal geometry theory, the number of pores with pore-throat radius greater than $r$ of the reservoir $N(r)$ and $r$ satisfies the following power ratio relation conditions in Equation (1) [38]:

$$
N(r<L)=\int_{r}^{r_{\max }} f(r) d r=C_{1} r^{-D_{f}}
$$

where $r_{\max }$ is the maximum pore-throat radius in the reservoir, $\mu \mathrm{m} ; f(r)$ is the probability density function; $N(r)$ is the number of pores of radius $r$; $L$ is the object size; $D_{f}$ is the fractal dimension of the microscopic pore structure, which is in the range of 2 to 3 ; $C_{1}$ is a constant.

Then, the micropore distribution of the reservoir has the fractal self-similar characteristics.

In this case, the fractal representation of pore-size distribution is as Equation (2) [39, 40]:

$$
F=\left(\frac{r}{r_{\max }}\right)^{3-D_{f}} .
$$

Correspondingly, the fractal representation of mercury

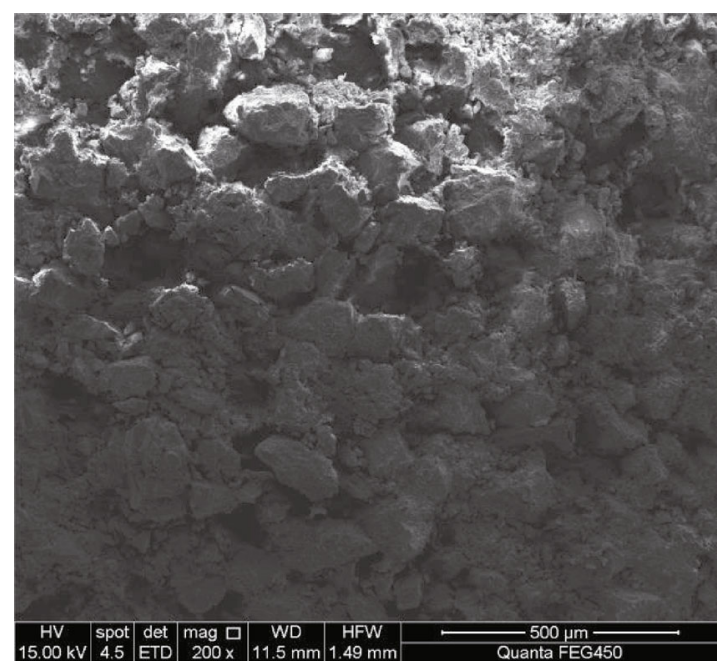

Figure 1: Enlarge image 200 times before water drive.

injection capillary pressure curve is as Equation (3):

$$
F=\left(\frac{p_{c}}{p_{\min }}\right)^{D_{f}-3}
$$

where $F$ is the wetting phase saturation of mercury injection capillary pressure curve under reservoir conditions, fraction; $p_{\min }$ is the capillary pressure corresponding to the maximum pore-throat radius in the mercury injection capillary pressure curve under reservoir conditions, namely, the inlet capillary pressure, $\mathrm{MPa} ; p_{c}$ is the capillary pressure, $\mathrm{MPa}$.

Take the logarithm of both sides of Equation (3) and we can get Equation (4):

$$
\lg F=\left(-D_{f}+3\right) \lg p_{\min }+\left(D_{f}-3\right) \lg p_{c} .
$$

According to Equation (4), it can be clearly seen that in $\log$-log coordinates, the wetting phase saturation $S$ has a linear relationship with capillary pressure $p_{c}$. Therefore, the linear regression analysis of Equation (4) can be carried out by combining the test data obtained from conventional mercury injection and constant rate mercury injection, and the fractal dimension $D_{f}$ can be obtained by the slope of the line. By the corresponding intercept, the capillary force $p_{\min }$ at the inlet and outlet can be obtained.

In order to truly reflect the distribution of pore structure of rock, the accuracy can be improved by using the method of piecewise fitting in the analysis of pore structure with great difference. In this paper, large pores and small pores are counted separately to calculate the fractal dimension of pore structure, respectively.

Then, the fractal models of pore distribution and capillary pressure curve are, respectively, as in Equation (5) and Equation (6).

For the larger pores,

$$
F=\left(\frac{r_{P}}{r_{P, \max }}\right)^{3-D_{P}}, F=\left(\frac{p_{P, c}}{p_{P, \text { min }}}\right)^{D_{P}-3},
$$




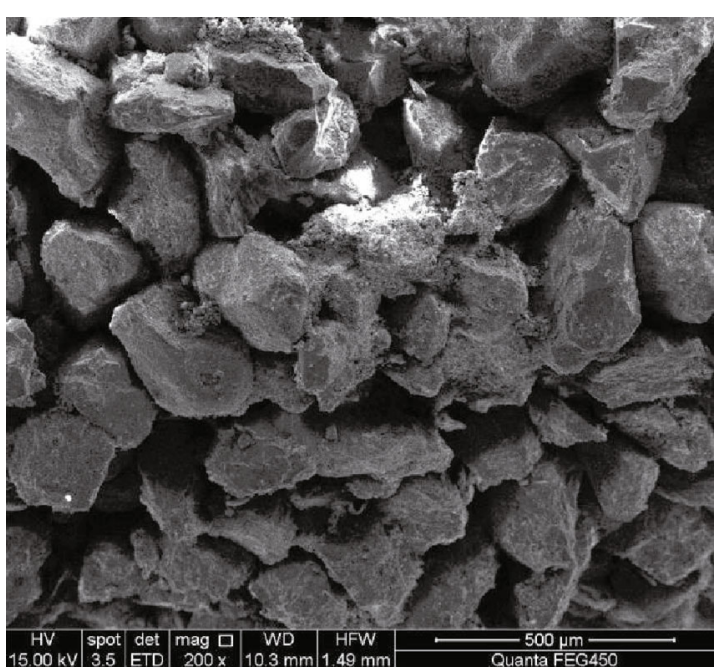

FIgURE 2: Enlarge image 200 times after water drive.

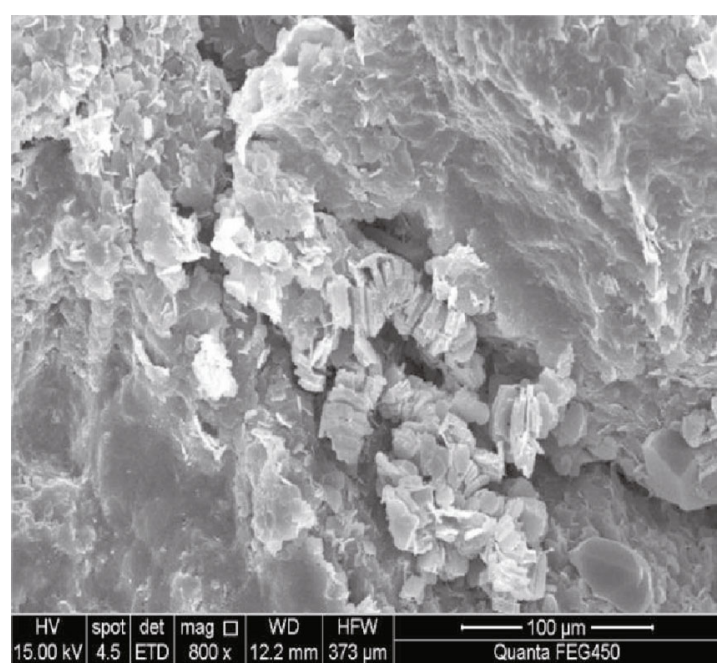

FIGURE 3: Enlarge image 800 times before water drive

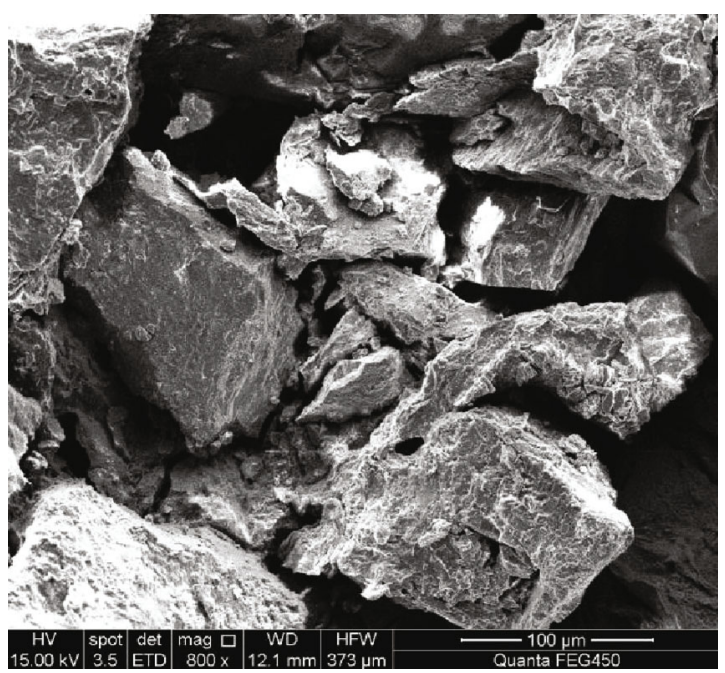

FIgURE 4: Enlarge image 800 times after water drive.

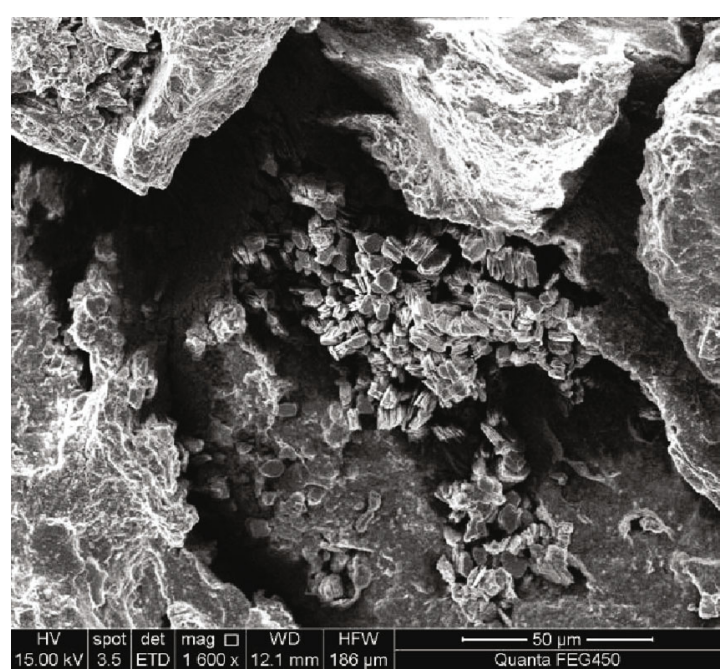

FIGURE 5: Enlarge images 2000 times before water drive.

and for the smaller pores,

$$
F=\left(\frac{r_{T}}{r_{T, \max }}\right)^{3-D_{T}}, F=\left(\frac{p_{T, c}}{p_{T, \min }}\right)^{D_{T^{-}-3}}
$$

where $D_{P}$ is the fractal dimension of larger pores; $D_{T}$ is the fractal dimension of smaller pores; $r_{P, \max }$ is the largest pore of larger pores, $\mu \mathrm{m} ; r_{T, \max }$ is the smallest pore of smaller pores, $\mu \mathrm{m} ; p_{P, \min }$ is the minimum capillary pressure corresponding to the larger pores on the capillary pressure curve, $\mathrm{MPa} ; p_{T, \text { min }}$ is the minimum capillary pressure corresponding to the smaller pores on the capillary pressure curve, $\mathrm{MPa} ; r_{P}$ is the pore radius of larger pores, $\mu \mathrm{m} ; r_{T}$ is the pore radius of smaller pores, $\mu \mathrm{m} ; p_{P, c}$ is the capillary pressure when the pore radius is $r_{P}, \mathrm{MPa} ; p_{T, c}$ is the capillary pressure when the pore radius is $r_{T}$, MPa.

\section{Results and Discussions}

3.1. Test Results of Core Pore Structure by SEM. In order to more clearly compare and analyze the changes of core pore structure before and after waterflooding, SEM scanning images were magnified by about 200 times, 800 times, and 1600 times, respectively, to conduct the related research work.

In Figures 1 and 2, the pore structures before and after waterflooding were imaged by scanning electron microscopy (SEM) at 200 times magnification. At low magnification, the clastic particles were well developed, and the clay mineral particles were closely arranged before waterflooding. The clastic rock particles were unevenly filled with argillaceous clay minerals, etc., with more content, more developed pores, and uneven distribution. After long-term waterflooding, core pores were more developed, intergranular pore connectivity was better, particle dissolution and quartz secondary enlargement were developed, and secondary intergranular pores were developed in pores. 


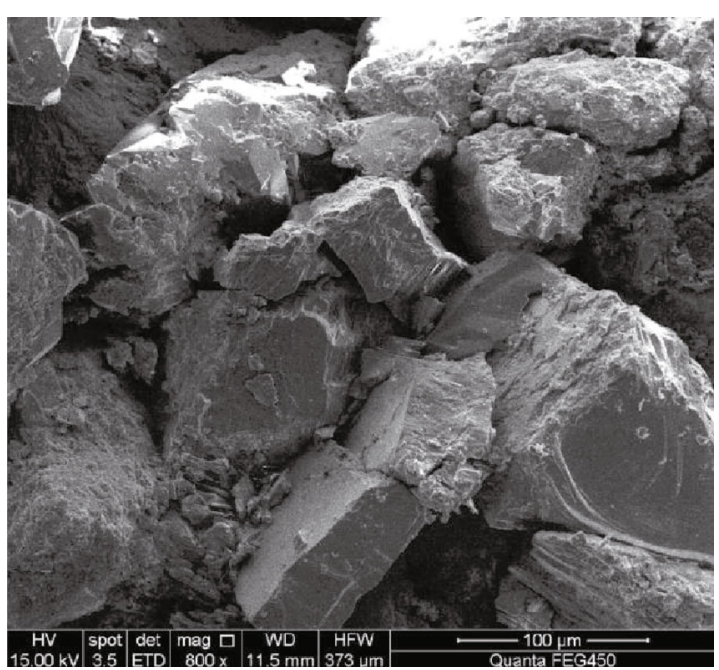

Figure 6: Enlarge images 2000 times after water drive.

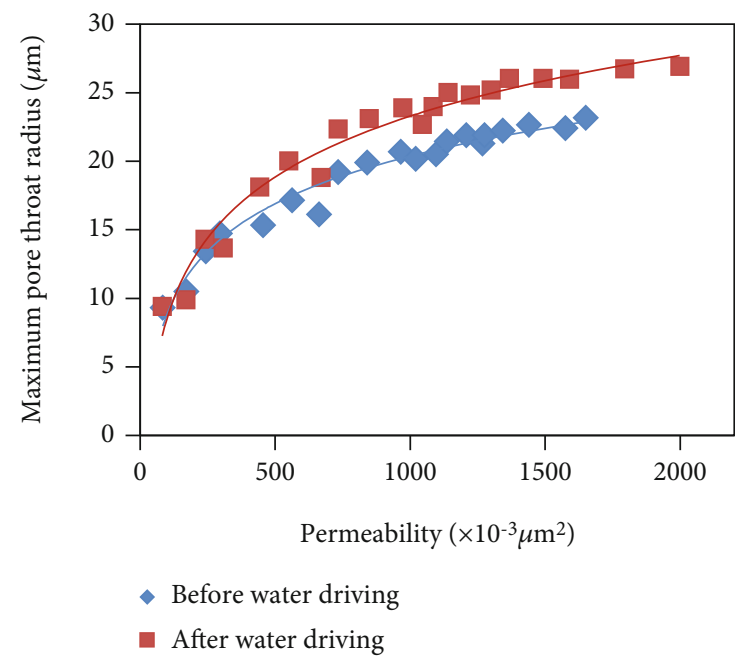

FIGURE 7: Relationship between the maximum pore-throat radius and permeability before and after water driving.

With the increase of magnification of core scanning electron microscope images, the mineral skeleton and filling components could be seen more obviously. Figures 3 and 4 showed the pore structure pictures of cores before and after waterflooding at a magnification of 800 times, respectively. Before waterflooding, it could be found that the clastic rocks were filled with leaf-like kaolinite and authigenic quartz, and the liritization was developed on the granules. The main component of the core was complete, and the phenomenon of feldspar damage and dissolution occurred locally. After waterflooding, it was obvious to observe the mineral skeleton left after the dissolution of minerals, and part of the clay minerals filled in the pores was washed away, and the average total amount of clay minerals decreased, which indicated that the overall pore structure inside the core had undergone a great change, from small pores to large and sublarge pores. The secondary development of quartz at the grain edge was increased, part of feldspar was broken, and the cements were

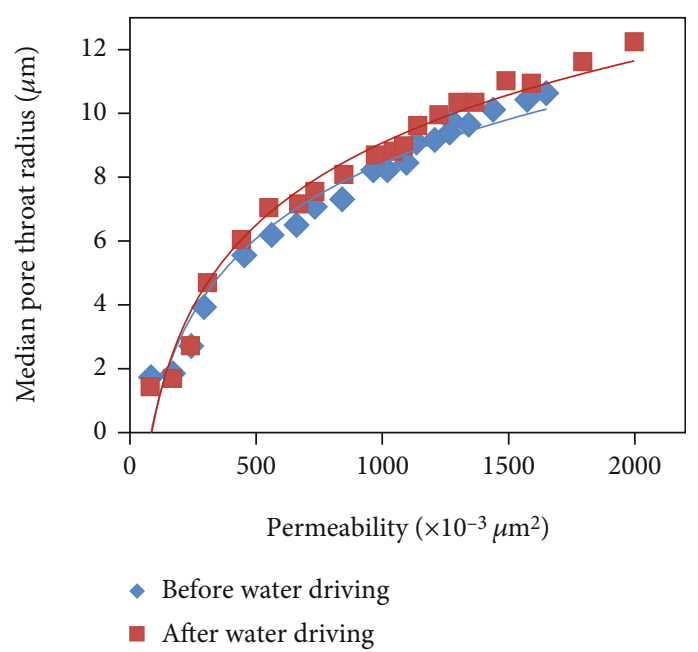

FIGURE 8: Relationship between the median pore-throat radius and permeability before and after water driving.

reduced. The local pores were also blocked due to clay mineral scouring and migration, making the pore roar smaller.

Figure 5 was the pore structure images of the core before waterflooding at a magnification of 2000 times. It could be observed that the pores were filled with kaolinite, with the presence of page-like, worm-like kaolinite and some chlorite. In addition, typical quartz could be seen, and the development of intergranular pores was not obvious. Figure 6 showed the pore structure images of the core after waterflooding at 2000 times magnification. Compared with that before waterflooding, it was observed that the dissolution of kaolinite in the pores was very obvious. The dissolved kaolinite fragments existed in the pores. There were few intact kaolinites in pieces. After alteration of feldspar, illite clay film was formed on the surface, and some quartz was secondary increased. Some secondary pores were formed, forming large pore channels, and the intergranular pores were enlarged.

In conclusion, before waterflooding, the reservoir pores were mainly intergranular pores with weak dissolution, smooth grain edges and developed mesopores, narrow distribution range, and single type. After long-term injection water erosion, reservoir properties changed. The dissolution and destruction of rock particles and the migration of original filling materials mainly expanded the intergranular pores and dissolution pores, and large intergranular pores, dissolution pores, and even macropores appeared, but there were also partly dissolved, broken content of settling down in the fine pore throat, made pore become smaller. Therefore, long-term water washing could increase the variation range of pore-throat distribution, with various types, macropore throat and micropore throat appeared and accompanied one after another, and the distribution of pores and throats were very different in vertical and transverse directions.

3.2. Results of Core Pore Structure by Mercury Injection Test before and after Waterflooding. In order to find out the influence of long-term waterflooding on the pore structure of cores in different permeability ranges, we selected 20 cores 


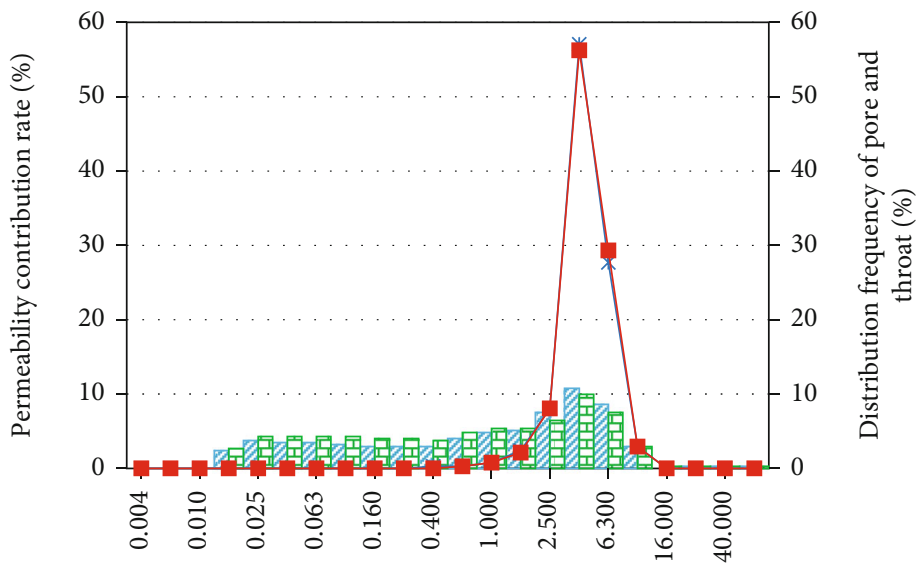

Pore and throat radius $(\mu \mathrm{m})$

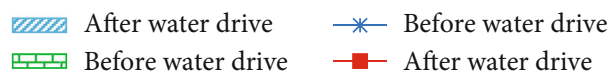

FIgURE 9: Pore-throat distribution frequency and permeability contribution before and after waterflooding $\left(k_{A}=195 \times 10^{-3} \mu \mathrm{m}^{2}\right)$.

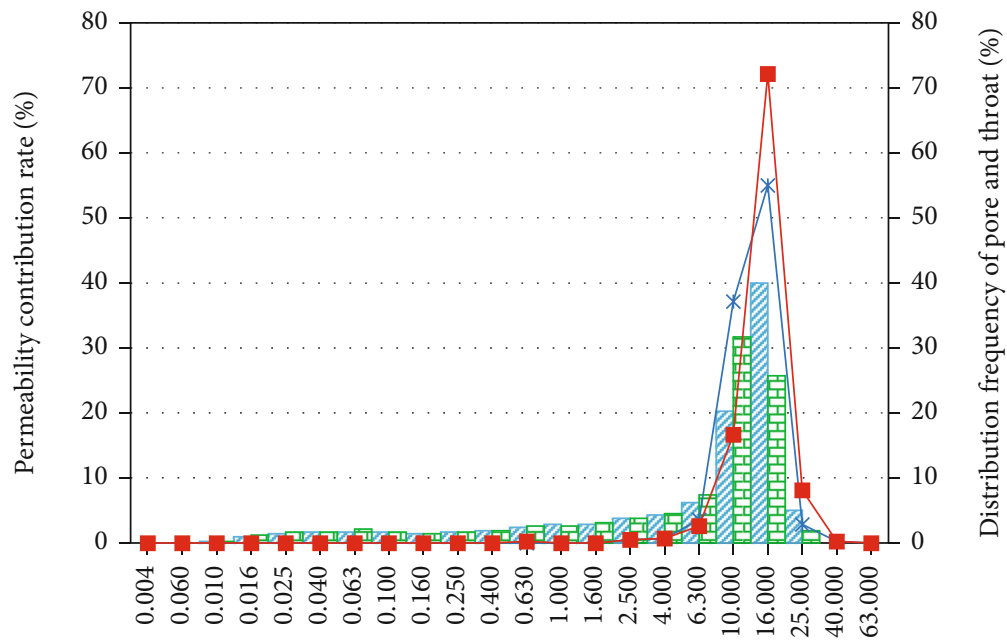

Pore and throat radius $(\mu \mathrm{m})$

$\begin{array}{ll}\text { After water drive } & \text { * } \\ \text { Before water drive }\end{array}$

FIGURE 10: Pore-throat distribution frequency and permeability contribution before and after waterflooding $\left(k_{A}=1610 \times 10^{-3} \mu \mathrm{m}^{2}\right)$.

from different types of reservoirs in the No. 1 oil production plant of Daqing Oilfield for this study. In addition, in order to ensure the accuracy of the experimental results, we performed long-term waterflooding on these core samples at standard displacement rates, and the injection volume was up to 1500 times the pore volume.

3.2.1. Changes of Permeability and Pore Radius before and after Waterflooding. Figure 7 showed the relationship between the maximum pore-throat radius and permeability of these core samples before and after waterflooding. Figure 8 shows the relationship between the median porethroat radius and permeability before and after waterflooding of these core samples.
The results showed that the pore-throat size of the reservoir changed obviously after long-term waterflooding. On the whole, the median and maximum pore-throat radius increased. It could be seen from Figures 7 and 8 that after long-term waterflooding, the median pore-throat radius of rock sample increased by $1.62 \mu \mathrm{m}$ and $0.97 \mu \mathrm{m}$ on average, with an increase of $15.2 \%$; the maximum pore-throat radius increased by $3.72 \mu \mathrm{m}$ and $2.64 \mu \mathrm{m}$ on average, with an increase of $12.9 \%$. Moreover, there was a good correlation between the median radius of pore throat and core permeability before and after waterflooding. As is known to all, the median value of pore-throat radius is an important index to evaluate the quality of reservoir, which reflects the lowest value of pore radius accounting for more than $50 \%$ of the 


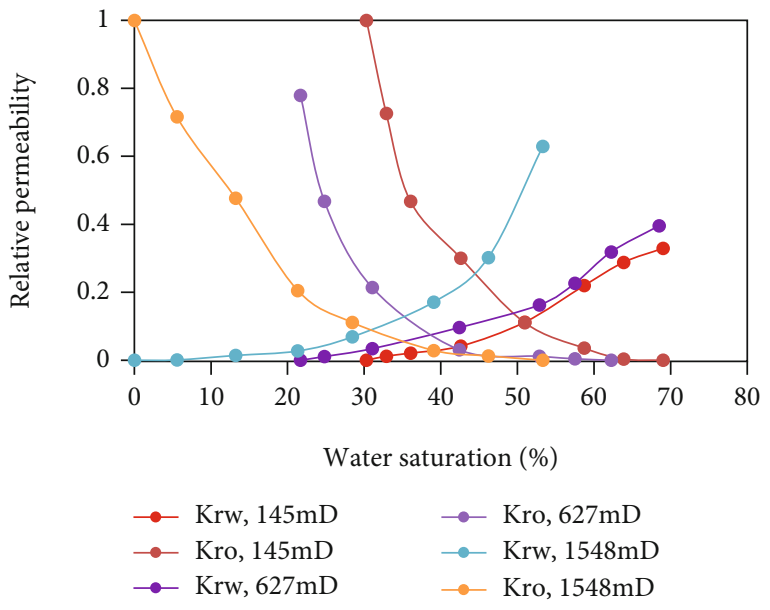

FIGURE 11: Imbibition and drainage relative permeability curves of type-I, type-II, and type-III.

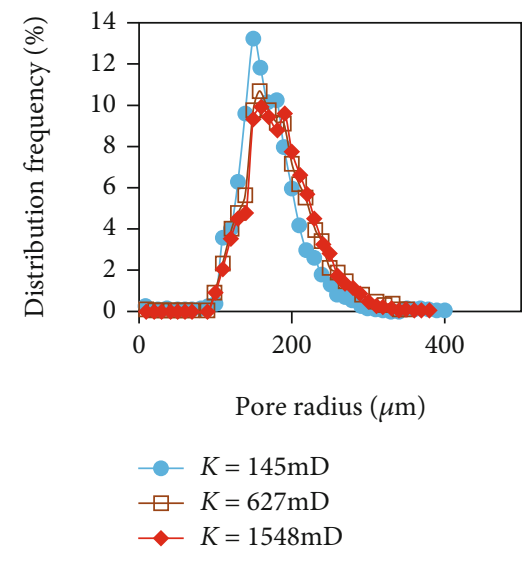

FIgURE 12: Pore radius before water driving.

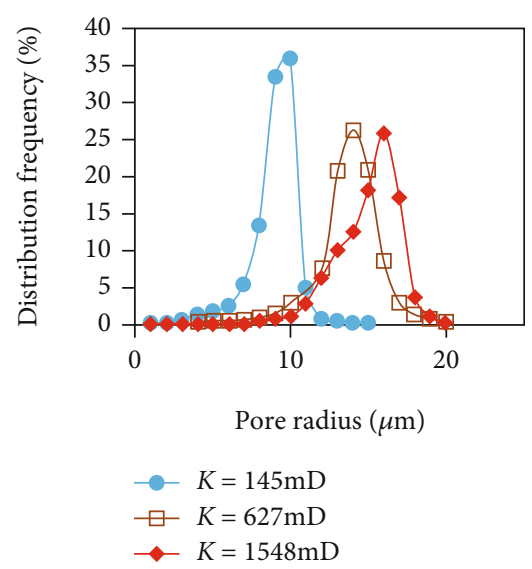

FIgURE 13: Throat radius before water driving.

pore volume of rock sample. That was to say, the increase of the median pore-throat radius indicated that the radius of large pore throat, which accounted for more than $50 \%$ of the pore volume of rock sample after waterflooding, was increasing. After long-term waterflooding, the pore-throat structure of sandstone changed, the pore-throat radius of reservoir increased, and the permeability was enhanced.

\subsubsection{Pore-Throat Distribution and Permeability} Contribution Rate before and after Waterflooding. In order to compare and analyze the variation of pore-throat distribution frequency and permeability contribution rate of rock samples with different permeability before and after waterflooding, the distribution variation of pore-throat distribution frequency and permeability contribution rate of rock samples with different permeability levels were compared and analyzed by using constant velocity mercury injection experimental parameters of rock samples. Figure 9 showed the distribution of pore-throat distribution frequency and permeability contribution rate before and after waterflooding, taking core A with lower permeability $\left(k=195 \times 10^{-3}\right.$ $\mu \mathrm{m}^{2}$ ) as an example. Figure 10 showed the distribution of pore-throat distribution frequency and permeability contribution rate before and after waterflooding, taking core $\mathrm{B}$ with higher permeability $\left(k=1610 \times 10^{-3} \mu \mathrm{m}^{2}\right)$ as an example.

The results showed that on the whole, for highpermeability core samples, the increase of pore-throat distribution frequency and permeability contribution rate after waterflooding was greater; on the contrary, for lowpermeability core samples, the change of pore-throat distribution frequency and permeability contribution rate before and after waterflooding was small or even slightly decreased. This was because the core with large permeability was denuded by fine particles after long-term waterflooding and forms more connected dominant seepage channels, which enhanced the flow ability of fluid and increases the apparent permeability. For the core with low permeability, the sorting of rock particles was poor, and the small particles stripped by long-term waterflooding had filled the larger holes to a certain extent, so it was possible to reduce the permeability.

3.2.3. Results of Constant Rate Mercury Injection Test. In Daqing Oilfield, three typical cores were taken from the type-I formation, the type-II formation, and the type-III formation, respectively, and the permeability was $145 \times 10^{-3}$ $\mu \mathrm{m}^{2}, 627 \times 10^{-3} \mu \mathrm{m}^{2}$, and $1548 \times 10^{-3} \mu \mathrm{m}^{2}$, respectively. The influence of long-term waterflooding on their respective pore-throat structure was analyzed. The original imbibition and drainage curves were shown in Figure 11. The pore distribution before water driving was shown in Figure 12, and the throat radius distribution before water driving was shown in Figure 13. Under different permeability conditions, the pore radius distribution of rock sample had no obvious change, and the pore structure distribution tended to be normal distribution. Different from this, the throat radius distribution of samples was different with different permeability and presented certain regularity. For the samples with high permeability, the throat radius distribution was relatively wide; for the samples with low permeability, the throat radius distribution became narrow, and the peak value was concentrated in the small throat. The throat radius corresponding to the throat distribution peak value of three rock samples with different permeability is $10.3 \mu \mathrm{m}, 14.7 \mu \mathrm{m}$, and $17 \mu \mathrm{m}$, 


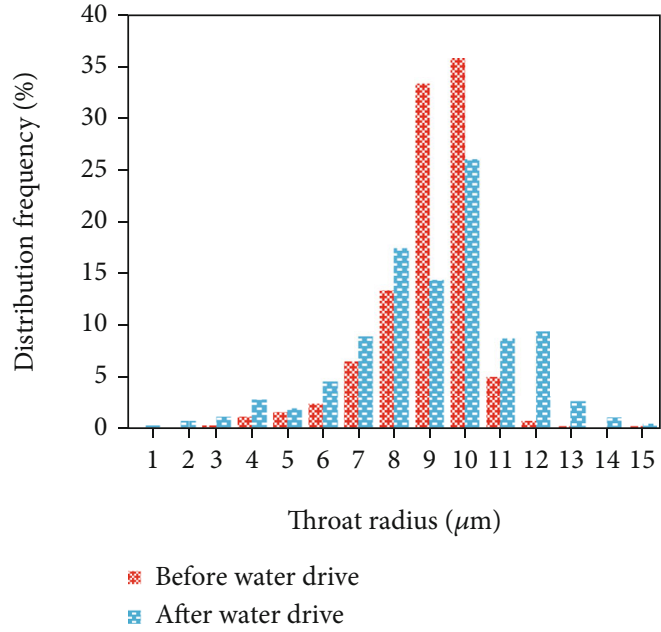

(a) $K=145 \times 10^{-3} \mu \mathrm{m}^{2}$

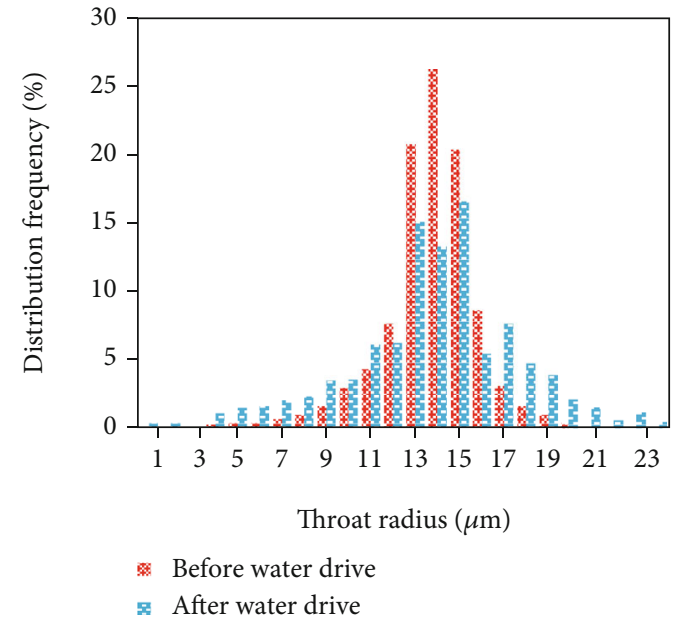

(b) $K=627 \times 10^{-3} \mu \mathrm{m}^{2}$

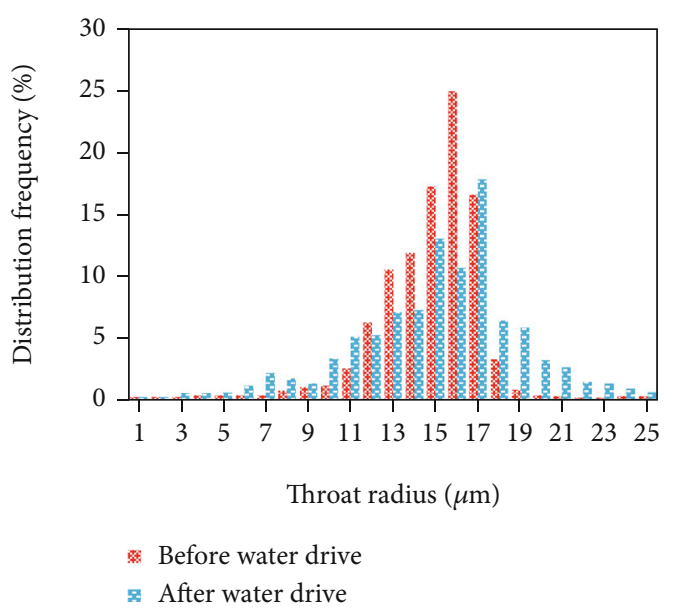

(c) $K=1548 \times 10^{-3} \mu \mathrm{m}^{2}$

FIGURE 14: Throat radius after water driving.

TABLE 1: The fractal dimension analysis results of different water cut stages of core B.

\begin{tabular}{|c|c|c|c|c|c|c|}
\hline Scope & Water cut & Slope & Intercept & $D$ & $p_{\min }(\mathrm{MPa})$ & $R^{2}$ \\
\hline \multirow{4}{*}{ Larger pores } & 0 & 0.5786 & 0.8422 & 2.437 & 0.036264 & 0.9919 \\
\hline & 0.75 & 0.6258 & 0.9183 & 2.3892 & 0.035141 & 0.9966 \\
\hline & 0.85 & 0.6597 & 0.9808 & 2.357 & 0.033487 & 0.9982 \\
\hline & 0.95 & 0.7393 & 1.1480 & 2.206 & 0.030154 & 0.9955 \\
\hline \multirow{4}{*}{ Smaller pores } & 0 & 0.1990 & 0.5192 & 2.801 & 0.001712 & 0.9988 \\
\hline & 0.75 & 0.1728 & 0.5545 & 2.827 & 0.000942 & 0.9972 \\
\hline & 0.85 & 0.1534 & 0.5908 & 2.844 & 0.000742 & 0.9980 \\
\hline & 0.95 & 0.1229 & 0.6202 & 2.878 & 0.000044 & 0.9968 \\
\hline
\end{tabular}

respectively, and the throat radius increased with the increase of rock sample permeability. This shows that the throat characteristics, rather than the pore characteristics, control the seepage characteristics of rock samples. The throat radius distribution of the cores above after water driving was shown in Figure 14.

According to Figure 14, the contribution of throat with small radius to permeability decreased in lower permeability core and increased slightly near the peak value, but some throat was blocked. For the medium permeability core, the pore passage of some throat was unobstructed due to the clay falling off after waterflooding, which enhanced the fluid seepage ability. It was possible that some relatively large throat appears after long-term waterflooding. For highpermeability core, the main flow path changed before and after waterflooding. The throat with radius of $1-11 \mu \mathrm{m}$ and 


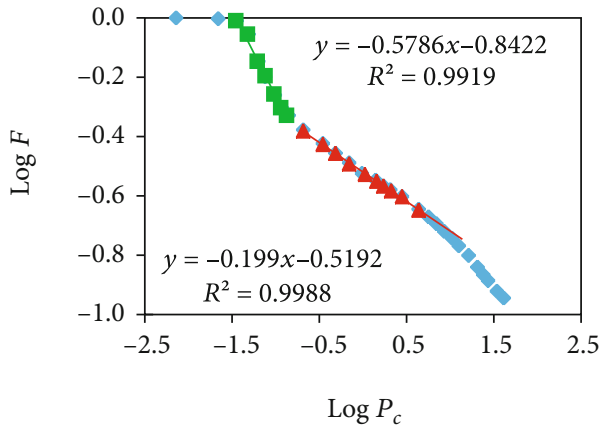

(a) Nonwater driving

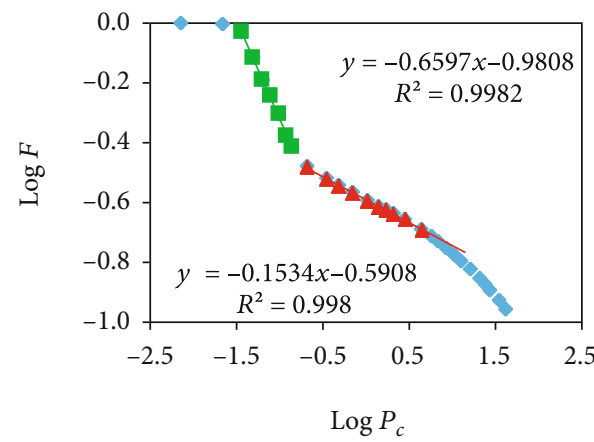

(c) Water cut of $85 \%$

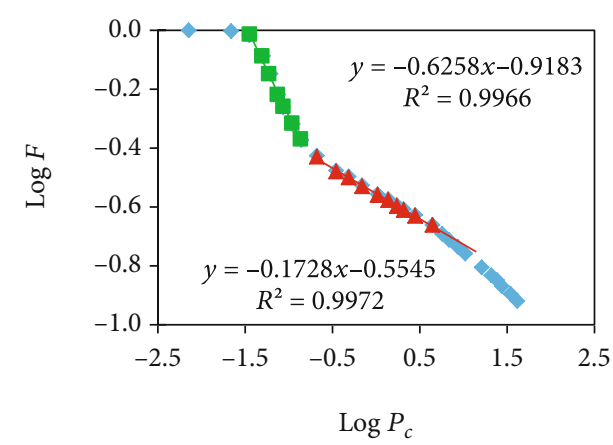

(b) Water cut of $75 \%$

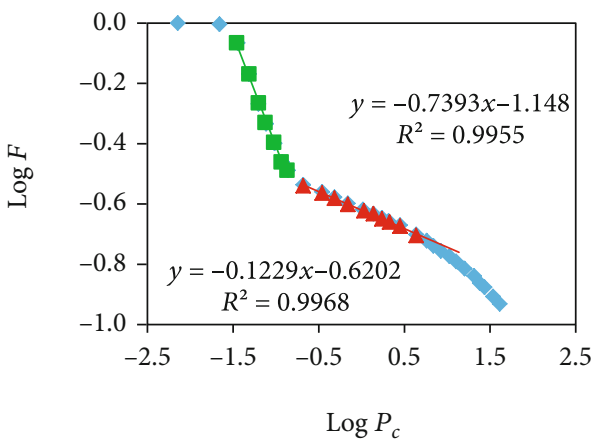

(d) Water cut of $95 \%$

FigURE 15: Double logarithm curves of core capillary pressure and water saturation.

$17-20 \mu \mathrm{m}$ increased the contribution to the flow after waterflooding, and there was a new throat with radius of 21-25 $\mu \mathrm{m}$, which indicated that the pore channel of some throat was unobstructed due to the clay falling off after waterflooding, so that the flow capacity of fluid was enhanced. It was possible that some relatively large throat appeared after waterflooding. At the same time, part of the pore throat was blocked. This showed that high-permeability reservoir was very conducive to the development of dominant permeability channel.

3.3. Fractal Description of Core Pore Structure after LongTerm Waterflooding. In order to study the influence of long-term waterflooding on micropore structure, it is necessary to calculate the fractal dimension of core pore structure at different water cut stages and analyze the fractal characteristics. Core sample B had experienced a long-term waterflooding experiment, which was taken as an example to analyze the influence of long-term waterflooding on micropore structure. Based on the constant pressure mercury injection experimental data of core sample B (permeability $1548 \times 10^{-3} \mu \mathrm{m}^{2}$ ) in four different water cut stages of initial nonwater driving, water driving at water cut of $75 \%$, water driving at water cut of $85 \%$, and water driving at water cut of $95 \%$, the fractal dimension of core pore was analyzed by Equation (4). Under the double logarithm coordinate system, $S_{w}$ and $p_{\min }$ should be in line with each other. The fractal dimension $D$ could be obtained from the slope of the straight line, and the entrance capillary force $p_{\min }$ could be obtained from the intercept.
The fractal characteristics of core pore structure in four water cut stages of core sample B were analyzed by twostage fitting method. The upper section reflected the pore structure characteristics of large pore throat and the lower section reflected the pore structure characteristics of small pore. The analysis results were shown in Figure 14. The fractal dimension analysis results of different water cut stages of core B were shown in Table 1.

According to Figure 15, the fractal dimension of macropore in different water cut stages was obviously smaller than that of small pore throat, which indicated that the pore structure of macropore throat was better than that of small pore throat; more importantly, after long-term waterflooding, the fractal dimension of macropore throat decreased with the increase of water cut, the macropore throat would become larger and larger, the inner wall would be smooth, and the homogeneity coefficient would increase; the fractal dimension of small pore throat would increase. The number increased with the increase of water content, reflecting the enhancement of micro heterogeneity driven by water. According to the analysis results of mercury injection data, with the increase of water cut after long-term waterflooding, the radius of pore throat increased, but the complexity of pore-throat structure increased. The macropore throat became larger and larger, and the micro heterogeneity of small pore throat became stronger and more complex. In this way, the injected water would preferentially enter into the macropore throat, which also created conditions for the formation to have a dominant channel. The change range of fractal dimension was small before the water content was 


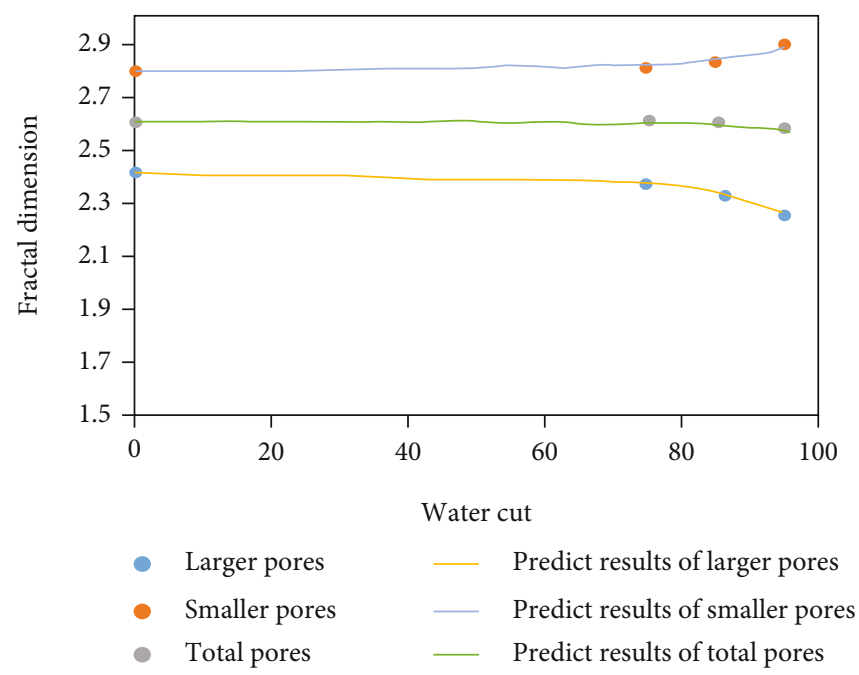

FIgURE 16: Comparison curves between actual data and prediction data of evolutionary model.

$75 \%$, but the change range of fractal dimension was large between $75 \%$ and $95 \%$.

The fractal dimension of macropore throat and pinhole throat had the following relation with the fractal dimension of total pore throat as shown in Equation (7).

$$
D_{\text {total }}=\frac{\left(D_{\text {high }}+D_{l o w}\right)}{2}
$$

where $D_{\text {total }}$ denotes the fractal dimension of total pore throat, $D_{\text {high }}$ denotes the fractal dimension of the larger pore throat, and $D_{\text {low }}$ denotes the fractal dimension of the smaller pore throat.

The formation process of macropore can be seen as two processes: the increase of local reservoir permeability and the decrease of local reservoir permeability at the same time. However, the microscopic essence of macropore is reflected in the change of fractal dimension of pore structure. Moreover, the evolution law of fractal dimension of pore structure with the change of water cut in different reservoir rock properties is different. Therefore, the reservoir pore structure is established. The mathematical model of dynamic evolution mode of fractal dimension of structure can combine macro and micro to quantitatively solve the problem of mathematical description of the formation and evolution of macropores.

Under the condition of short-term waterflooding in Daqing Oilfield, the effect of injected water on reservoir erosion and immersion is not obvious, which shows that the fractal dimension of reservoir rock changes little in the initial stage, and it belongs to a gentle increasing stage. With the increase of injected water and waterflooding time, the long-term erosion and immersion of injected water has a great effect on pore structure. However, due to the limitation of rock cementation strength and clay content, the change of reservoir fractal dimension tends to be gentle from the end of ultrahigh water cut to $98 \%$ water cut. In general, the evolution of fractal dimension of pore structure in Daqing Oilfield is first gentle, then rising, and then gentle. According to the change of fractal dimension, the exponential evolution model can be used to characterize the evolution of fractal dimension in the middle and low water cut stage, but after the high water cut stage, the change model of fractal dimension can be established according to the half rising half ridge distribution function [41] as shown in Equation (8) and Equation (9).

For the reservoir dominated by larger pores and throats,

$D= \begin{cases}D_{\max } e^{-C_{1} f_{w}} & f_{w} \leq 80 \%, \\ D_{\max }-D_{\max } \lambda_{D \max }\left\{\frac{1}{2}-\frac{1}{2} \sin \left(\frac{\pi}{1-1 / 2}\left(f_{w}-\frac{1+1 / 2}{2}\right)\right)\right\} & 80 \%<f_{w} \leq 98 \%,\end{cases}$

and for the reservoir dominated by smaller pores and throats,

$D= \begin{cases}D_{\min } e^{C_{1} f_{w}} & f_{w} \leq 80 \%, \\ D_{\min }+D_{\min } \lambda_{D \min }\left\{1 / 2+1 / 2 \sin \left(\frac{\pi}{1-1 / 2}\left(f_{w}-\frac{1-1 / 2}{2}\right)\right)\right\} & 80 \%<f_{w} \leq 98 \%,\end{cases}$

where $D_{\min }$ and $D_{\max }$ are both the fractal dimension at the water cut of $75 \% ; C_{1}$ is a fractal coefficient; $\lambda_{D \text { max }}$ denotes a multiple decrease of fractal dimension, which is determined by rock properties; $\lambda_{D \text { min }}$ denotes a multiple increase of fractal dimension, which is determined by rock properties; $f_{w}$ denotes the water cut, fraction.

Based on the fractal evolution model of pore structure under different water cut conditions, the relationship between fractal dimension and water cut was calculated by using the data in Table 1, as shown in Figure 16. It can be seen that the fractal evolution mathematical model of pore throat is in good agreement with the actual test data. Therefore, it can quantitatively characterize the evolution of fractal dimension of reservoir micropore structure. 


\section{Conclusions}

(1) Long-term waterflooding will lead to the dissolution of some minerals; part of the clay minerals filled in the pores will be washed away, the average total amount of clay minerals will be reduced, the overall pore structure of the core has changed greatly, and most of the pores will become larger. At the same time, due to the erosion and migration of clay minerals, local pores are also blocked, making a small part of pores smaller

(2) Long-term waterflooding and scouring will cause complex changes in the microscopic pore structure of the reservoir, and the overall pore characteristics will tend to become better. The connectivity of larger pores becomes better, and the degree of heterogeneity decreases. On the contrary, the microscopic heterogeneity of small pores becomes stronger and stronger. In general, the heterogeneity of the reservoir with low porosity and permeability increases with the passage of water injection time. These evolutionary characteristics will undoubtedly lead to the injected water preferring to enter the larger pores and throats, which will create conditions for the formation of dominant channels

(3) Based on the fractal theory and the evolution model of pore structure in different water cut stages during long-term water injection, a micropore-throat structure evolution model of core was established, and the mathematical relationship between water cut and fractal dimension of pore structure of core was obtained, which quantitatively characterized the complexity and evolution law of pore structure. The larger the fractal dimension was, the more serious the microscopic heterogeneity was

\section{Data Availability}

The data used to support the findings of this study are included within the article.

\section{Conflicts of Interest}

The authors declare that they have no conflicts of interest regarding the publication of this paper.

\section{Acknowledgments}

This research was supported by the National Natural Science Foundation of China (Youth Project) (Grant No. 51804076), Heilongjiang Provincial Natural Science Foundation (Youth Project) (Grant No. QC2018047), Youth Science Foundation of Northeast Petroleum University (Grant No. 2019NL-02), and Research Initiation Foundation of Northeast Petroleum University (Grant No. 2019KQ15).

\section{References}

[1] L. Zhu, Q. Du, X. Jiang et al., "Characteristics and strategies of three major contradiction for continental facies multi-layered sandstone reservoir at ultra-high water cut stage," Acta Petrolei Sinica, vol. 36, no. 2, pp. 210-216, 2015.

[2] Q. Du, "Variation law and microscopic mechanism of permeability in sandstone reservoir during long-term water flooding development," Acta Petrolei Sinica, vol. 37, no. 9, pp. 11591164, 2016.

[3] J. Q. Chen, Q. Q. Wang, J. H. Xiao et al., “Development status and prospect of water pre-separation technology for produced liquid in high water-cut oil well," Acta Petrolei Sinica, vol. 41, no. 11, pp. 1434-1444, 2020.

[4] Q. L. Du, B. Q. Song, and L. H. Zhu, "Challenges and countermeasures of the waterflooding development for Lasaxing Oilfields during extra-high watercut period," Petroleum Geology \& Development in Daqing, vol. 38, no. 5, pp. 189-194, 2019.

[5] H. L. Bian, J. Guan, Z. Q. Mao, X. D. Ju, and G. Q. Han, "Pore structure effect on reservoir electrical properties and well logging evaluation," Applied Geophysics, vol. 11, no. 4, pp. 374383, 2014

[6] R. G. Loucks, "Revisiting the importance of secondary dissolution pores in tertiary sandstones along the Texas Gulf Coast," Gulf Coast Association of Geological Societies Transactions, vol. 55, pp. 447-455, 2005.

[7] Y. Li, J. Yang, Z. Pan, and W. Tong, "Nanoscale pore structure and mechanical property analysis of coal: an insight combining AFM and SEM images," Fuel, vol. 260, article 116352, 2020.

[8] J. Yan, X. He, S. Zhang et al., "Sensitive parameters of NMR T2 spectrum and their application to pore structure characterization and evaluation in logging profile: a case study from Chang 7 in the Yanchang Formation, Heshui area, Ordos Basin, NW China," Marine and Petroleum Geology, vol. 111, pp. 230-239, 2020.

[9] L. Hao-ran, H. Xu-ri, Y. cheng, and T. Zheng-wu, "Study of low-permeability sandstone by unidirectional mercury intrusion porosimetry," Chemistry and Technology of Fuels and Oils, vol. 54, no. 4, pp. 476-483, 2018.

[10] L. Zhang, J. Li, H. Tang, and J. Guo, "Fractal pore structure model and multilayer fractal adsorption in shale," Fractals, vol. 22, no. 3, article 1440010, 2014.

[11] Y. Yang and S. Liu, "Estimation and modeling of pressuredependent gas diffusion coefficient for coal: a fractal theorybased approach," Fuel, vol. 253, pp. 588-606, 2019.

[12] N. Golsanami, X. Zhang, W. Yan et al., "NMR-based study of the pore types' contribution to the elastic response of the reservoir rock," Energies, vol. 14, no. 5, pp. 1513-1538, 2021.

[13] J. H. M. Thomeer, "Introduction of a pore geometrical factor defined by the capillary pressure curve," Journal of Petroleum Technology, vol. 12, no. 3, pp. 73-77, 1960.

[14] L. Leal, R. Barbato, A. Quaglia, J. C. Porras, and H. Lazarde, "Bimodal behavior of mercury-injection capillary pressure curve and its relationship to pore geometry, rock-quality and production performance in a laminated and heterogeneous reservoir," in SPE Latin American and Caribbean Petroleum Engineering Conference, Buenos Aires, Argentina, 2001.

[15] C. Zhang, Y. Cheng, and C. Zhang, “An improved method for predicting permeability by combining electrical measurements and mercury injection capillary pressure data," Journal of Geophysics and Engineering, vol. 14, no. 1, pp. 132-142, 2017. 
[16] N. Golsanami, E. Bakhshi, W. Yan et al., "Relationships between the geomechanical parameters and Archie's coefficients of fractured carbonate reservoirs: a new insight," Energy Sources, Part A: Recovery, Utilization, and Environmental Effects, vol. 2, pp. 1-25, 2020.

[17] C. Guan, W. Hu, Y. Li, R. Ma, and Z. Ma, "Prediction of oilwater relative permeability with a fractal method in ultrahigh water cut stage," International Journal of Heat and Mass Transfer, vol. 130, pp. 1045-1052, 2019.

[18] S. Y. Wu, "Variation rule of oil layer parameters washed by long-term injected water and its impact on development effect," Petroleum Geology and Recovery Efficiency, vol. 11, no. 2, pp. 9-11, 2004.

[19] S. F. Yin, "Variation characteristics of the reservoir parameters in the development course of the waterflooding for the distributary channel sandbodies," Petroleum Geology \& Oilfield Development in Daqing, vol. 34, no. 4, pp. 69-72, 2015.

[20] Y. Li, "Variation rule of macro parameters and dynamic model of oil reservoirs in continental faulted basin," Acta Petrolei Sinica, vol. 26, no. 2, pp. 65-68, 2005.

[21] S. W. Tyler and S. W. Wheatcraft, "Fractal processes in soil water retention," Water Resources Research, vol. 26, no. 5, pp. 1047-1054, 1990.

[22] B. Yu and J. Li, "Some fractal characters of porous media," Fractals, vol. 9, no. 3, pp. 365-372, 2001.

[23] Z. Wu, C. Cui, Y. Ye, X. Cheng, and J. Trivedi, “A fractal model for quantitative evaluating the effects of spontaneous imbibition and displacement on the recovery of tight reservoirs," Journal of Petroleum Science and Engineering, vol. 198, article 108120, 2021.

[24] A. J. Katz and A. H. Thompson, "Fractal sandstone pores: implications for conductivity and pore formation," Physical Review Letters, vol. 54, no. 12, pp. 1325-1328, 1985.

[25] B. B. Mandelbrot, The Fractal Geometry of Nature, Freeman, New York, 1983.

[26] B. Yu, "Analysis of flow in fractal porous media," Applied Mechanics Reviews, vol. 61, no. 5, article 50801, 2008.

[27] R. F. Angulo, V. Alvarado, and H. Gonzalez, "Fractal dimensions from mercury intrusion capillary tests," in SPE Latin America Petroleum Engineering Conference, Caracas, Venezuela, 1992.

[28] G. Perez and A. K. Chopra, "Evaluation of fractal models to describe reservoir heterogeneity and performance," SPE Formation Evaluation, vol. 12, no. 1, pp. 65-72, 1997.

[29] P. P. Shen, M. X. Liu, and F. S. Jia, "Application of fractal techniques in reservoir development," in SPE International Oil and Gas Conference and Exhibition in China, Beijing, China, 1998.

[30] K. W. Li, "Characterization of rock heterogeneity using fractal geometry," in SPE International Thermal Operations and Heavy Oil Symposium and Western Regional Meeting, Bakersfield, California, 2004.

[31] K. Li and R. N. Horne, "Fractal modeling of capillary pressure curves for the geysers rocks," Geothermics, vol. 35, no. 2, pp. 198-207, 2006.

[32] K. Li and H. Zhao, "Fractal prediction model of spontaneous imbibition rate," Transport in Porous Media, vol. 91, no. 2, pp. 363-376, 2012.

[33] Y. Chen, C. Shen, P. Lu, and Y. Huang, "Role of pore structure on liquid flow behaviors in porous media characterized by fractal geometry," Chemical Engineering and Processing: Process Intensification, vol. 87, pp. 75-80, 2014.
[34] X. Chen, G. Yao, C. Luo et al., "Capillary pressure curve determination based on a $2-\mathrm{D}$ cross-section analysis via fractal geometry: a bridge between 2-D and 3-D pore structure of porous media," Journal of Geophysical Research: Solid Earth, vol. 124, no. 3, pp. 2352-2367, 2019.

[35] E. P. Verrecchia, "On the relationship between the pore-throat morphology index ("a") and fractal dimension (D f) of pore networks in carbonate rocks; discussion," Journal of Sedimentary Research, vol. 65, no. 4a, pp. 701-702, 1995.

[36] L. Kouqi, O. Mehdi, and K. Lingyun, "Fractal and multifractal characteristics of pore throats in the Bakken Shale," Transport in Porous Media, vol. 126, pp. 579-598, 2019.

[37] Y. Jin, W. Z. Quan, J. H. Qin, X. H. Liu, J. L. Zheng, and H. B. Song, "Quantitative characterization of complex assembly in fractal pore-throat porous media," Meitan Xuebao/Journal of the China Coal Society, vol. 45, no. 5, pp. 1845-1854, 2020.

[38] W. Li, H. Zhao, S. Li, W. Sun, L. Wang, and B. Li, “A fractal model of effective stress of porous media and the analysis of influence factors," Results in Physics, vol. 8, pp. 920-925, 2018.

[39] W. Hua, Nonlinear Percolation Mechanism and Dynamic Evaluation Model of Thief Zone at Ultra-High Water Cut Stage, Northeast Petroleum University, 2017.

[40] B. Xiao, J. Fan, and F. Ding, "Prediction of relative permeability of unsaturated porous media based on fractal theory and Monte Carlo simulation," Energy \& Fuels, vol. 26, no. 11, pp. 6971-6978, 2012.

[41] Z. H. Dai, Y. Liu, X. Q. Qiu, and J. S. Han, "Condition evaluation approach of protective devices based on fuzzy comprehensive evaluation with variable weight," Electrical Measurement \& Instrumentation, vol. 58, no. 4, pp. 150-157, 2021. 